\title{
Hormonal Regulation of the MHC Class I Gene in Thyroid Cells: Role of the Promoter "Tissue-Specific" Region
}

\author{
Cesidio Giuliani ${ }^{1,2 *}$, Sara Verrocchio ${ }^{1,2}$, Fabio Verginelli ${ }^{2,3}$, Ines Bucci ${ }^{1,2}$, \\ Antonino Grassadonia ${ }^{2,4}$ and Giorgio Napolitano ${ }^{1,2}$
}

1 Unit of Endocrinology, Department of Medicine and Sciences of Aging, University "G. d'Annunzio" of Chieti-Pescara, Chieti, Italy, ${ }^{2}$ Centre for Advanced Studies and Technology (CAST), University "G. d'Annunzio" of Chieti-Pescara, Chieti, Italy, ${ }^{3}$ Department of Pharmacy, University "G. d'Annunzio" of Chieti-Pescara, Chieti, Italy, ${ }^{4}$ Department of Oral, Medical and Biotechnological Science, University "G. d'Annunzio" of Chieti-Pescara, Chieti, Italy

OPEN ACCESS

Edited by:

Noriyuki Koibuchi,

Gunma University, Japan

Reviewed by:

Koichi Suzuki,

Teikyo University, Japan

Anne H. Van Der Spek,

Weill Cornell Medicine, United States

*Correspondence:

Cesidio Giulian

cesidio.giuliani@unich.it

Specialty section:

This article was submitted to

Thyroid Endocrinology,

a section of the journal

Frontiers in Endocrinology

Received: 29 July 2021 Accepted: 15 November 2021 Published: 06 December 2021

Citation:

Giuliani $C$, Verrocchio $S$, Verginelli $F$,

Bucci I, Grassadonia A and Napolitano G (2021) Hormonal

Regulation of the MHC Class I Gene in Thyroid Cells: Role of the Promoter "Tissue-Specific" Region.

Front. Endocrinol. 12:749609. doi: 10.3389/fendo.2021.749609
In previous studies we have demonstrated that the expression of the Major Histocompatibility Complex (MHC) class I gene in thyrocytes is controlled by several hormones, growth factors, and drugs. These substances mainly act on two regions of the MHC class I promoter a "tissue-specific" region (-800 to $-676 \mathrm{bp}$ ) and a "hormone/ cytokines-sensitive" region (-500 to -68 bp). In a previous study, we have shown that the role of the "tissue-specific" region in the MHC class I gene expression is dominant compared to that of the "hormone/cytokines-sensitive" region. In the present report we further investigate the dominant role of the "tissue-specific" region evaluating the effect of thyroid stimulating hormone (TSH), methimazole (MMI), phenylmethimazole (C10), glucose and thymosin- $\alpha 1$. By performing experiments of electrophoretic mobility shift assays (EMSAs) we show that TSH, MMI and C10, which inhibit MHC class I expression, act on the "tissue-specific" region increasing the formation of a silencer complex. Glucose and thymosin- $\alpha 1$, which stimulate $\mathrm{MHC}$ class I expression, act decreasing the formation of this complex. We further show that the silencer complex is formed by two distinct members of the transcription factors families activator protein-1 (AP-1) and nuclear factorkB (NF-kB), c-jun and p65, respectively. These observations are important in order to understand the regulation of $\mathrm{MHC}$ class I gene expression in thyroid cells and its involvement in the development of thyroid autoimmunity.

Keywords: major histocompatibility complex class I (MHC-1), NF-kB, AP-1, thyroid, c-jun, p65, hormonal regulation

\section{INTRODUCTION}

Several studies have demonstrated that Major histocompatibility complex (MHC) class I as well as class II overexpression on non-immune cells are important in the development of autoimmune diseases and thyroid autoimmunity (1-9). Thus, there is an increased expression of MHC class I and II molecules in pancreatic $\beta$ islet cells of patients with type 1 diabetes mellitus, in muscle biopsies of patients with inflammatory myopathies, and in thyrocytes from patients with autoimmune thyroid 
diseases $(3,5,7)$. MHC class I overexpression is an early feature of the experimental-induced thyroiditis and this suggests its pathogenetic role in the autoimmune process $(10,11)$. Furthermore, MHC class I expression is necessary for the induction of systemic lupus erythematosus (SLE) and type 1 diabetes mellitus in experimental models of these diseases $(1,2)$. Indeed, down-regulation or absence of MHC class I expression is considered the hallmark of tissue immune privilege $(4,12)$. Regarding the thyroid, previous studies have demonstrated that hormones and growth factors that regulate thyroid cell growth and function, such as thyroid stimulating hormone (TSH), hydrocortisone, insulin and insulin-like growth factor-I (IGF-I) decrease MHC class I expression in a coordinate and specific way $(7,13,14)$. Of note is that MHC class I expression is also decreased by iodide, phorbol esters, transforming growth factor (TGF)- $\beta 1$, and methimazole (MMI), whereas it is increased by $\alpha$-and $\gamma$-interferons (IFNs), thymosin- $\alpha 1$, and high levels of glucose (15-21). The specific regulation of MHC class I gene by these substances is particularly intriguing since the level of expression of MHC class I molecules differs between tissues, with the highest expression in lymphoid tissues and lower expression in some tissues as endocrine glands, skeletal muscle, myocardium, or gastric mucosa $(22,23)$. We believe that the levels of MHC class I molecules are lower in tissues that have potential autoantigens. Regarding the thyroid, we have hypothesized that the decrease of MHC class I molecules on the surface of thyrocytes by several hormones and factors, may be an important mechanism to preserve thyroid self-tolerance and prevent autoimmune thyroid disease. Indeed, the same hormones and factors increase the transcription of thyroid specific genes that can act as potential autoantigens $(7,16,17)$. These data assume a particular importance considering the possibility that innate immune activation can lead to an autoimmune response. Pivotal studies have demonstrated that thyroid cells have functional pattern recognition receptors (PRRs), such as toll-like receptors (TLRs) and retinoic acidinducible gene (RIG)-like receptors, that respond to various pathogen-associated molecular patterns (PAMPs) or damageassociated molecular patterns (DAMPs) $(8,24)$. Therefore, it has been hypothesized that the presence of PAMPs or DAMPs into thyroid cells can trigger an innate immune response, and eventually make thyrocytes to behave as antigen-presenting cells and to initiate an autoimmune response $(25,26)$. Experiments conducted in FRTL-5 cells have shown that the release of genomic ds DNA by injury activate several genes involved in the immune response including the MHC class I gene (26). We think that this mechanism is also true for other tissues expressing normally low levels of MHC class I molecules. Indeed, in patients with type 1 diabetes MHC class I overexpression is associated with pancreatic islets infiltration by cytotoxic $\mathrm{T}$ lymphocytes specific for autoantigens (27). Moreover, some further studies suggest that MHC class I overexpression is the trigger of immune-mediated myopathies $(28,29)$.

Given these data, we believe it is noteworthy that we know the regulation of MHC class I expression in thyroid cells to better understand the pathogenesis of autoimmune thyroid diseases and to detect how hormones and drugs can modulate the gene expression.

Previous studies have defined the 5' flanking region of the PD1 gene a swine classical MHC Class I gene whose properties are maintained when it is transfected into cells from different species $(13-15,17-20,24,30-32)$. It has got two main regions that control the expression of MHC class I gene in a particular cell (Figure 1). The "tissue-specific" region, with overlapping enhancer and silencer elements, is -800 to $-676 \mathrm{bp}$ from the start of transcription; it sets the constitutive level of Class I expression in each tissue. The "hormone/cytokines-sensitive" region," -500 to $-68 \mathrm{bp}$, is responsible for the regulation of class I expression within each tissue and is modulated by the hormones, growth factors, drugs and cytokines mentioned above $(6,16)$. Table 1 shows the effects of different hormones, growth factors, cytokines and drugs on the MHC class I promoter activity in the thyroid cell line FRTL-5, as described in previous studies (13-15, 17-20, 30). For all these compounds,

A

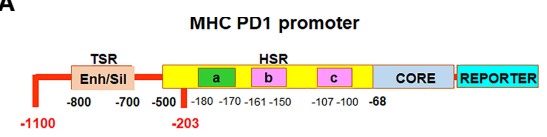

B

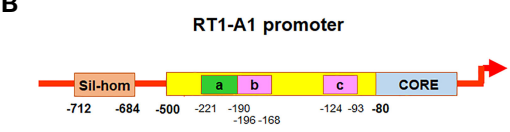

C "TISSUE-SPECIFIC" REGION OF MHC PD1

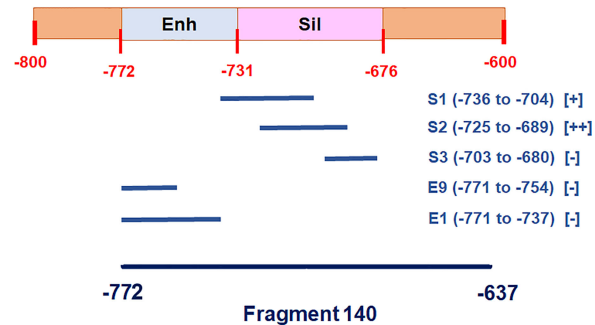

FIGURE 1 | Diagrammatic representation of the MHC class I gene promoters. (A), diagrammatic representation of the pig MHC class I PD1 promoter (6, 16). TSR: "tissue-Specific" Region including an overlapping enhancer and silencer (enh/sil) elements; HSR: "hormones/cytokines-sensitive" region including: the enhancer $A(a)$, the interferon response element (b), the CRE-like element (c), the core promoter containing CAAT and TATAA-like elements (CORE); REPORTER: indicate the reporter gene used in previous studies for functional analysis by CAT or luciferase assays. (B), diagrammatic representation of the rat MHC class I RT1-A1 gene promoter (Ensembl gene accession number: ENSRNOG00000038999). Sil-hom: a region homologous to the PD1 silencer of the "tissue-Specific" region; a: enhancer A, b: an overlapping interferon response element, c: enhancer B containing a CRE-like element, CORE: a region containing CAAT and TATAA elements; the arrow indicates the start of transcription. (C), detailed diagram of the "tissue -specific" region of the MHC class I PD1 promoter, the relative positions of the oligonucleotides used as competitors in are indicated, as well as that of the 140 fragment used as labeled probe. [+] and [-] indicate presence or absence of competition, respectively. 
TABLE 1 | Effects of the indicated compounds on the MHC class I promoter activity.

\begin{tabular}{|c|c|c|c|}
\hline Compound & $p(-1100)$ & $p(-203)$ & Reference \\
\hline $\mathrm{TSH}$ & Decrease & Decrease & (13) \\
\hline Hydrocortisone & Decrease & Decrease & $(14)$ \\
\hline Insulin/IGF-1 & Decrease & Increase & (30) \\
\hline$\alpha$-and $\gamma$-Interferons & Increase & Increase & $(14,18)$ \\
\hline lodide & Decrease & Decrease & (15) \\
\hline TGF- $\beta 1$ & Decrease & Decrease & (19) \\
\hline Thymosin- $\alpha 1$ & Increase & Increase & (20) \\
\hline Glucose & Increase & Increase & (18) \\
\hline Methimazole & Decrease & Decrease & (17) \\
\hline Phenylmethimazole & Decrease & Decrease & (17) \\
\hline
\end{tabular}

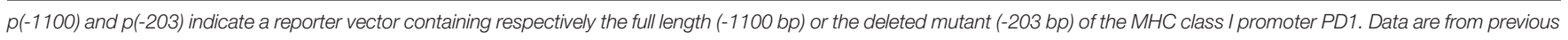
studies $(13-15,17-20,30)$.

except insulin and IGF-1, there is a similar effect both in the full length promoter $-1100 \mathrm{bp}$ from the start of transcription and in the deleted mutant -203 bp from the start of transcription, which lacks the "tissue-specific" region but retains the "hormone/ cytokines-sensitive" region (see Figure 1A). Experiments performed with reporter vectors containing mutations of one of the responsive elements of the "hormone/cytokines-sensitive" region [the enhancer $A$, the Interferon response element or the cyclic-AMP response (CRE)-like element], showed a loss of the effect of the related compounds and allowed the identification of this region $(13-15,17-20,30)$. Furthermore, the disparate response of insulin and IGF-1 between the full length promoter and the deleted mutant $\mathrm{p}(-203) \mathrm{bp}$, have shown a dominant role of the upstream "tissue-specific" region in regulating the MHC class I gene transcription (30). The functional relationship between these two regulatory regions has been confirmed by the observation that insulin and IGF-1 lose their inhibitory effect on the activity of a full length MHC class I promoter that lacks the enhancer A element. Furthermore, electrophoretic mobility shift assays (EMSAs) have shown that both the "tissue-specific" region and the "hormone/cytokinessensitive" region (particularly the enhancer A and the interferon response elements) interact with different members of the same family of transcription factors, nuclear factor-kB (NF-kB) and activator protein-1 (AP-1) (13-20, 30). In detail, the silencer element of the "tissue-specific" region interacts with the p65 subunit of NF-kB and c-jun, whereas the enhancer A element binds a protein complex named Mod-1 consisting of the p50 subunit of NF-kB and fra- 2 .

As shown in Table 1, the MHC class I gene expression is decreased by TSH, MMI and C10, whereas it is increased by glucose and thymosin- $\alpha 1$. These compounds act on the "hormone/cytokines-sensitive" region of the MHC class I promoter. In more detail, TSH, MMI and C10 induce the formation of specific protein/DNA complexes with a silencer sequence between -127 and -90 bp containing a CRE-like site $(13,17)$, whereas glucose and thymosin- $\alpha 1$ induce the formation of a protein/DNA complex, named Mod-1, with the Enhancer A sequence between -180 and -170 bp $(18,20)$. Since we have previously observed that the upstream "tissue-specific" region has got a dominant role in the regulation of MHC class I gene expression by insulin and IGF-1 (30), we have planned to evaluate the effects of TSH, MMI, C10, glucose and thymosin$\alpha 1$ on this region.

In the present manuscript we illustrate that TSH, MMI, C10, glucose and thymosin- $\alpha 1$ act on the "tissue-specific" region of the MHC class I promoter modifying the formation of the silencer complex made up of two distinct members of the transcription factors families AP-1 and NF-kB, c-jun and p65 respectively. The effects of the aforementioned compounds on the silencer complex formation is consistent with those produced on the MHC class I gene expression. This observation further suggests that in the FRTL-5 cells the "tissue-specific" region acts as a dominant regulatory element of MHC class I promoter.

\section{MATERIALS AND METHODS}

\section{Materials}

C10 was a gift from Intherthyr Research Corporation (Marietta, OH, USA) (17). Thymosin- $\alpha 1$ was kindly provided by SciClone Pharmaceuticals Inc (Foster City, CA, USA). $\left[\gamma^{32}\right.$ P]ATP (3000 $\mathrm{Ci} / \mathrm{mmol})$ and $\left[\alpha_{-}{ }^{32} \mathrm{P}\right]-\mathrm{dCTP}(3000 \mathrm{Ci} / \mathrm{mmol})$ were from Perkin Elmer Italia (Monza, Italy). Heat-treated, mycoplasma-free calf serum was from Life Technologies Europe (Monza, Italy). For EMSAs we used antibodies against the p65 (sc-8008) and p50 (sc-8414) subunits of NF-kB, c-jun (sc74543), and normal mouse IgG (sc-2025) as negative control (Santa Cruz Biotechnology Inc., Santa Cruz, CA, USA). The oligonucleotides S1, S2, S3, E1 and E9 were kindly provided by Dr. Dinah S. Singer (National Cancer Institute, NIH, Bethesda, MD, USA). Chromatin immunoprecipitation was carried out by using the following antibodies: NF-kB p65 (L8F6) mouse mAb, NF-kB p105/50 (D4P4D) rabbit $\mathrm{mAb}$, c-Jun (60A8) rabbit $\mathrm{mAb}$ and normal rabbit or mouse IgG as negative control (Cell Signaling Technology Inc., Danvers, MA, USA). The source of all other materials was the Sigma Aldrich Co. (St. Louis, MO, USA), unless otherwise specified.

\section{Cell Culture}

The F1 subclone of FRTL-5 rat thyroid cells (American Type Culture Collection, CRL-8305) was a gift from the Interthyr Research Foundation (Marietta, OH, USA). Cells were grown in $6 \mathrm{H} 5 \%$ medium consisting of Coon's modified Ham's F-12 
medium supplemented with $5 \%$ calf serum, $2 \mathrm{mM}$ glutamine, $1 \mathrm{mM}$ nonessential amino acids, and a six-hormone $(6 \mathrm{H})$ mixture: $1 \mathrm{mU} / \mathrm{mL}$ bovine TSH, $10 \mu \mathrm{g} / \mathrm{mL}$ insulin, $0.4 \mathrm{ng} / \mathrm{mL}$ cortisol, $5 \mathrm{mg} / \mathrm{mL}$ transferrin, $10 \mathrm{ng} / \mathrm{mL}$ glycyl-L-histidyl-Llysine acetate, and $10 \mathrm{ng} / \mathrm{mL}$ somatostatin. These cells were diploid, between the $5^{\text {th }}$ and $25^{\text {th }}$ passage, and had all of the functional properties described previously $(13-15,17-21,24,30$, $33-38)$. Fresh $6 \mathrm{H} 5 \%$ medium was added to the cells every 2 to 3 days, and they were passaged every 7 days. In individual experiments, cells were grown to $60 \%$ confluence in $6 \mathrm{H} 5 \%$ medium and then shifted to the appropriate treatment condition as previously reported $(17,18,30)$. For the insulin treatment, cells were shifted to a three-hormone $(3 \mathrm{H})$ medium (i.e., with no TSH, insulin, or hydrocortisone) with only $0.2 \%$ calf serum $(3 \mathrm{H} 0.2 \%) \pm$ insulin $10 \mu \mathrm{g} / \mathrm{ml}$ for 7 days. For the treatment with MMI, C10 and TSH, cells were shifted to a five-hormone $(5 \mathrm{H})$ medium (i.e., without TSH) with $5 \%$ calf serum $(5 \mathrm{H} 5 \%$ medium) for 7 days to become quiescent, and then treated with MMI $5 \mathrm{mM}$, C10 $0.5 \mathrm{mM}$, or TSH $0.1 \mathrm{nM}$ for 36 hours. In the experiments performed with thymosin- $\alpha 1$ and glucose, cells were shifted to $5 \mathrm{H} 5 \%$ medium for 7 days to become quiescent, then they were cultured in $6 \mathrm{H} 5 \%$ medium \pm thymosin- $\alpha 11 \mu \mathrm{g} /$ $\mathrm{mL}$ for 12 hours, or $6 \mathrm{H} 0.2 \%$ medium \pm glucose $30 \mathrm{mM}$ for 48 hours. The latter low serum medium was chosen to avoid a potential effect by variable concentrations of the glucose contained in the calf serum.

\section{Cell Extracts}

Cellular extracts were prepared by a modification of described methods (39). In brief, cells were washed twice in cold PBS, $\mathrm{pH}$ 7.4 , scraped, and centrifuged $(500 \mathrm{xg})$. The cell pellet was resuspended in 2 volumes of Dignam buffer C [25\% glycerol, $20 \mathrm{mM}$ 4-(2-hydroxyethyl)-1-piperazineethanesulfonic acid (HEPES-KOH), pH 7.9, $1.5 \mathrm{mM} \mathrm{MgCl} 2,0.42 \mathrm{M} \mathrm{NaCl}, 0.5 \mathrm{mM}$ dithiothreitol, $1 \mu \mathrm{g} / \mathrm{ml}$ leupeptin, $1 \mu \mathrm{g} / \mathrm{ml}$ pepstatin and $0.5 \mathrm{mM}$ phenylmethylsulfonyl fluoride]. The final $\mathrm{NaCl}$ concentration was adjusted based on cell pellet volume to $0.42 \mathrm{M}$. Cells were lysed by repeated cycles of freezing and thawing. The extracts were centrifuged $(100,000 \mathrm{xg})$ at $4^{\circ} \mathrm{C}$ for 20 minutes. The supernatant was recovered, aliquoted and stored at $-70^{\circ} \mathrm{C}$.

\section{EMSAs}

The generation and preparation of the $-140 \mathrm{bp}$ probe and of the S1, S2, S3, E1 and E9 oligonucleotides were previously described $(30,31)$. Their sequences are reported in Table 2 . The $-140 \mathrm{bp}$ probe was labeled with $\left[\gamma_{-}{ }^{32} \mathrm{P}\right] \mathrm{ATP}$ using T4 polynucleotide kinase (New England Biolabs, Ipswich, MA, USA), then purified on an $8 \%$ native polyacrylamide gel. EMSAs were performed as previously described $(14,30)$. Binding reactions in low salts and no detergent included $1.5 \mathrm{fmol}\left[{ }^{32} \mathrm{P}\right] \mathrm{DNA}, 3 \mu \mathrm{g}$ cell extract and $3 \mu \mathrm{g}$ poly $(\mathrm{dI}-\mathrm{dC})$ in $10 \mathrm{mM}$ Tris-Cl, $\mathrm{pH} 7.9,1$ $\mathrm{mM} \mathrm{MgCl2,} 1 \mathrm{mM}$ dithiothreitol (DTT), $1 \mathrm{mM}$ ethylendiaminotetraacetic acid (EDTA), and 5\% glycerol in a $20 \mu \mathrm{l}$ total volume. Incubations were performed at room temperature for $30 \mathrm{~min}$. Where indicated unlabeled oligonucleotides or antibodies were added to the binding reaction and incubated with the extracts for 20 minutes prior
TABLE 2 | Sequences (5'-3') of the MHC class I PD1 promoter 140 fragment and of oligonucleotides S1, S2, E1 and E9 used as competitors in the EMSAs.

\section{0 fragment (-772 -637)}

GGTCCACATTCAAAATAACCTIGAGAAATTACCATAATGATAGCATCCAAAATT ATCTGAAAAGGTTATTAAAATACATGTCCTACATGTGTGCGGGGCПTIACATा TCATAGATGTCAGCCACCAAAAGGAG

S1 oligonucleotide (-740 -700)

CGCGAATGATAGCATCCAAAATTATCTGAAAAGGTTAGCGC

s2 oligonucleotide (-727 -687)

GGCCAAAATTATCTGAAAAGGTTATTAAAAATACATGTCGG

E1 oligonucleotide (-772 -733)

GGTCCACATTCAAAATAACCTITGAGAAATTACCATCGCG

E9 oligonucleotide (-772 -746)

GGTCCACATTCAAAATAACAGGAGㅁGㅡㅡ

In blue the region -772 -732 spanning the enhancer element, in red the region -731-676 spanning the silencer element. In italic and underlined are mutated nucleotides. See also ref. 31.

the addition of labeled DNA. Following incubations, reaction mixtures were electrophoresed on $4.5 \%$ native polyacrylamide gels at $160 \mathrm{~V}$ in $0.5 \mathrm{x}$ TBE at room temperature. Gels were dried and autoradiographed. Binding activity was quantified by optical densitometry using a STORM 860 Imager (Molecular Dynamics, GE Healthcare Italy, Milan, Italy) and data are shown in Table 3.

\section{RNA Isolation and Northern Analysis}

RNA was prepared using a RNeasy Mini kits (Qiagen Inc., Valencia, CA, USA). Twenty $\mu \mathrm{g}$ of the different RNA samples were run on denaturing agarose gels, capillary blotted on Nytran membranes (Schleicher \& Schuell-Whatman, Florrham Park, NJ, USA), UV cross-linked, and hybridized by using QuickHyb Hybridization Solution (Stratagene, La Jolla, CA, USA), following the manufacturer protocol. The probes were labeled with $[\alpha-32 \mathrm{P}]-\mathrm{dCTP}$ using Ladderman Labeling kits (Takara Mirus Bio, Madison, WI, USA). The MHC class I probe was a $1.0 \mathrm{~kb}$ HpaI fragment of the MHC class-I pH 7 clone spanning the entire cDNA insert (40). The $\beta$-actin probe was as described previously (40). Quantitation was performed using the STORM 860 Imager (Molecular Dynamics).

\section{Chromatin Immunoprecipitation (ChIP) Assay}

ChIP was performed using SimpleChIP enzymatic chromatin IP kit (Cell Signaling Technology Inc.) following the manufacturer

TABLE 3 | Densitometric analysis of the EMSAs shown in Figure 2A and Figures 3A, B, C.

\begin{tabular}{lc}
\hline Treatment & Band intensity (arbitrary unit) \\
\hline Control 3H0.2\% & 100 \\
+ Insulin & $289 \pm 7.2^{\star}$ \\
Control $5 \mathrm{H} 5 \%$ & 100 \\
$+\mathrm{MMl}$ & $267 \pm 8.4^{\star}$ \\
$+\mathrm{C} 10$ & $269 \pm 6.6^{\star}$ \\
+ TSH & $233 \pm 9.1^{\star}$ \\
Control 6H5\% & 100 \\
+ Thymosin- $\alpha 1$ & $58 \pm 5.0^{\star}$ \\
Control 6H0.2\% & 100 \\
+ Glucose & $44 \pm 6.9^{\star}$ \\
\hline
\end{tabular}

The intensity of each relative control is set to 100. Data are means \pm S.D from three independent experiments. ${ }^{*} p<0.05$ compared to relevant control. 
instructions. In brief, FRTL-5 cells cultured in $3 \mathrm{H} 0.2 \% \pm$ insulin $10 \mu \mathrm{g} / \mathrm{ml}$ for 7 days, as described above, were crosslinked for $10 \mathrm{~min}$ at room temperature by $1 \%$ formaldehyde. Nuclear DNA was digested by Micrococcal nuclease and nuclei were lysed by ultrasonic homogenizer. The complexes were purified by ChIP grade protein G agarose and the crosslinks were reversed incubating the samples with 200 $\mathrm{mM} \mathrm{NaCl}$ and $120 \mu \mathrm{g}$ of Proteinase $\mathrm{K}$ for 2 hours at $65^{\circ} \mathrm{C}$. Chromatin immunoprecipitation was performed with the antibodies indicated above, DNA was purified and analyzed using real-time quantitative PCR (qPCR).

\section{qPCR Analysis}

qPCR was performed using SimpleChIP Universal qPCR master mix (Cell Signaling Technology Inc.) and a primer pair (forward: 5'-TCAAGGCCAGCTTGGTCTAC-3'; reverse: 5'CAGCAGCCCAGCAGCCTC-3') flanking a region of the rat MHC class I gene RT1.A1 (Ensembl gene accession number: ENSRNOG00000038999) homologous to the silencer element of the "tissue-specific" region of the PD1 promoter used in the EMSAs. Each sample was run, in triplicate, in a QuantStudio 7 PRO Real-Time PCR System (Applied Biosystem, ThermoFisher Scientific, Waltham, MA, USA) and the immunoprecipitation efficiency was calculated using the percent input method.

\section{Other Assays}

Protein concentrations were determined using BCA protein assay kits (Pierce Biotechnology Inc., Rockford, IL, USA), with crystalline BSA as standard.

\section{Statistical Analysis}

All experiments were repeated at least three times with independent batches of cells. The quantitative data obtained by optical densitometry were evaluated as means \pm S.D. The significance between experimental values was determined by unpaired twotailed t-test or two-way ANOVA, with $\mathrm{p}<0.05$ or better when the data from all of the experiments were considered.

\section{RESULTS}

\section{EMSAs Indicate That the Functional Effects of TSH, Glucose, Thymosin $\alpha-1$, MMI and C10 on MHC Class I Gene Expression Correlate With Changes in Binding of DNA/Protein Complexes to the "Tissue-Specific" Region of the PD1 Promoter}

We have performed EMSA experiments using a radiolabeled probe with a sequence encompassing the MHC class I promoter between -772 to $-637 \mathrm{bp}$, termed 140 fragment because of its total length (including nucleotides from restriction sites on either end). This fragment encloses the overlapping enhancer and silencer elements of the "tissue-specific" region previously described $(31,32)$. As previously showed (30), the addition of insulin $10 \mu \mathrm{g} / \mathrm{ml}$ to the FRTL-5 cells maintained in a $3 \mathrm{H}$ medium culture (i.e., no TSH, insulin, or hydrocortisone and containing only $0.2 \%$ calf serum) increased the formation of a slowing complex (Figure 2A lane 3, arrow; Table 3) similar to a previous identified silencer of the promoter transcription $(31,32)$. This treatment decreased the MHC class I RNA level (Figure 2B) as already observed in previous studies (41).

The identification of this complex with the silencer element previously described $(30,31)$ was confirmed by competition experiments. Indeed, the preincubation of the cellular extracts with unlabeled double-strand oligonucleotides, spanning the functional silencer element previously identified and named S1 and S2 $(30,31)$ (Figure 1C) inhibited its formation (Figure 2Clanes 2 and $3 v$ s. 1, respectively). This inhibition was specific since two oligonucleotides, corresponding to the enhancer portion of the "tissue-specific" regions (Figure 1C), named E1 and E9 (31) did not decrease the complex (Figure 2Clanes 4 and $5 v s$. 1, respectively). It must be emphasized that high levels of this silencer complex are associated with low levels of MHC class I expression (6, 30-32). EMSAs experiments performed by using extracts from cells treated with TSH, MMI, C10, glucose and thymosin- $\alpha 1$, confirmed the consistency between the silencer formation and the expression of the MHC class I gene (Figure 3). Indeed, cellular extracts from cells cultured in $5 \mathrm{H}$ medium (i.e. without $\mathrm{TSH}$ ) and $5 \%$ calf serum treated with compounds that cause a decrease of MHC class I expression, as MMI $5 \mathrm{mM}$, or C10 $0.5 \mathrm{mM}$, or TSH $0.1 \mathrm{nM}$, showed an increase of the silencer complex (Figure 3A lanes 2, 3, 4 vs. 1, respectively; Table 3). Conversely, cellular extracts from cells treated with compounds that cause an increase of MHC class I expression, as thymosin- $\alpha 11 \mu \mathrm{g} / \mathrm{mL}$ or glucose $30 \mathrm{mM}$, showed a decrease of the silencer complex (Figure 3B lane 2 vs. 1 and Figure 3C lane 2 vs. 1, respectively; Table 3). The choice of treatment conditions is based on our previous experiments (17, $18,20)$ and are detailed in the Materials and Methods section. Figure 3D shows the effect of these treatments on the MHC class I RNA level, which confirm our previous studies

Cell extracts from FRTL-5 cells maintained in $6 \mathrm{H} 5 \%$ medium were then preincubated with antibodies against the p65 subunit of NF-kB and c-jun. This experiment has shown a decrease of the silencer complex (Figure 4, lanes 2 and 3 respectively), whereas no effect was seen using antibodies against the p50 subunit of NF-kB (Figure 4, lane 4 vs. 1). This decrease indicates an involvement of c-jun and p65 in the formation of the silencer complex as previously observed using extracts from FRTL-5 cells treated with IGF-1 or insulin (30).

\section{ChIP Assay Confirms the Binding of c-jun and the p65 Subunit of NF-kB to the "Tissue-Specific" Region of the Rat MHC Class I Promoter}

EMSAs, although very useful for analyzing the interaction between transcription factors and specific DNA sequences, it has the limit of carrying out the reaction in a test tube. Therefore, we have evaluated in vivo using ChIP assay the interaction between $\mathrm{c}$-jun and the p65 subunit of NF-kB with a region of the promoter of the rat MHC class I (RT1-A1 gene) homologous to the silencer element of the "tissue-specific" region of the MHC 


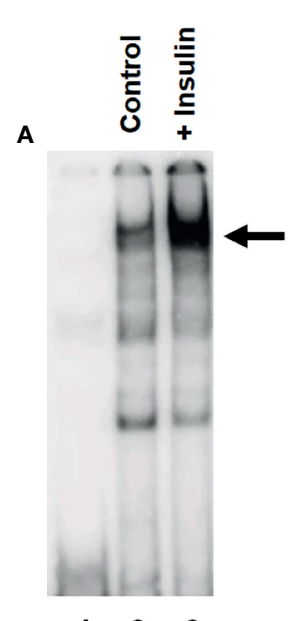

$\begin{array}{lll}1 & 2 & 3\end{array}$

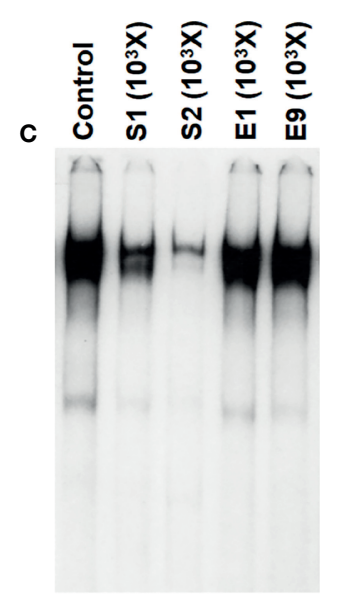

$\begin{array}{lllll}1 & 2 & 3 & 4 & 5\end{array}$

B

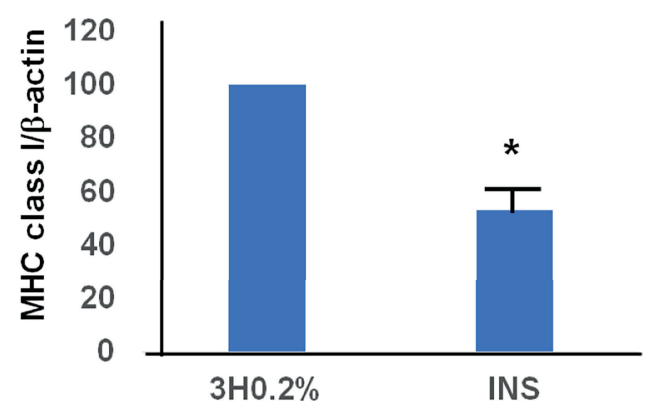

FIGURE 2 | Representative EMSAs showing the effect of insulin on the formation of the silencer element. (A), EMSAs were performed, as detailed in Material and Methods, using cellular extracts from FRTL-5 and the -140 bp probe that spans the region between -772 to -637 bp from the transcription start site (this fragment encloses the overlapping enhancer and silencer elements of the "tissue-specific" region). Lane 1, radioactive probe alone; lane 2 is the incubation of radioactive probe with extracts from control cells ( $3 \mathrm{H} 0.2 \%$ medium); lane 3 is the incubation of radioactive probe with extracts from cells in $3 \mathrm{H} 0.2 \%$ medium + insulin $10 \mu \mathrm{g} /$ $\mathrm{ml}$. The arrow indicates the protein-DNA complex identified as the silencer element. (B), effect of insulin treatment on MHC class I RNA levels. FRTL-5 cells were grown and treated as in the EMSAs shown in (A). Data are means MHC class-I/B-actin \pm S.D. expressed as percentages of control from three separate experiments, ${ }^{*} \mathrm{p}<0.05$ compared to control. INS, cells in $3 \mathrm{H} 0.2 \%$ medium + insulin $10 \mu \mathrm{g} / \mathrm{ml}$. (C), EMSAs were performed, as detailed in Material and Methods, using cellular extracts from FRTL-5 and the -140 bp probe that spans the region between -772 to -637 bp from the transcription start site. Lane 1 is the incubation of radioactive probe with extracts from cells maintained in 3H 0.2\% medium + insulin $10 \mu \mathrm{g} / \mathrm{ml}$; lanes 2 to 5 show the effect of the unlabeled oligonucleotides S1, S2, E1 and E9 (1000 fold excess) on the complex formation. Data are from a representative experiment repeated three times with similar results.

class I PD1 promoter. The cross-linked chromatin complex was obtained from FRTL-5 cells treated with $3 \mathrm{H} 0.2 \% \pm$ insulin 10 $\mu \mathrm{g} / \mathrm{ml}$ for 7 days and immunoprecipitation was performed using antibodies against the rat $\mathrm{c}$-jun and the rat $\mathrm{p} 65$ subunit of NF-kB. The purified DNA was then analyzed by qPCR using primers flanking the rat homologous silencer element. As shown in Figure 5 the experiment confirmed the binding of the transcription factors c-jun and the p65 subunit of NF-kB with this region and the treatment with insulin increased the proteinDNA interaction as observed with EMSAs. No effect was seen in using antibodies against the rat p50 subunit of NF-kB.

\section{DISCUSSION}

Several studies performed in the past have demonstrated the effects of various hormones, growth factors, cytokines and drugs on MHC class I gene expression. They have also shown that these compounds act on a region between -500 to $-68 \mathrm{bp}$, therefore called "hormone/cytokines-sensitive" region. This region has got several enhancer and silencer elements as illustrated in Figure 1. In more details, those studies have shown that some compounds such as TSH, MMI and C10 act inducing the formation of two protein-DNA complexes on a region that includes the constitutive 38 bp silencer of the MHC class-I promoter, which contains a CRE-like sequence $(11,15)$. Other compounds as hydrocortisone, insulin/IGF-1, TGF- $\beta 1$, thym and glucose act regulating the binding of the Mod-1 complex with the enhancer A element $(12,16-18,22)$. In most cases, an increase in Mod-1 binding stimulates the gene transcription, while a decrease inhibits it. However, we have previously observed (22) that although insulin or IGF-1 makes Mod-1 binding increase it leads the transcription of the MHC class I gene to be reduced. This discrepancy was explained by the observation that insulin 

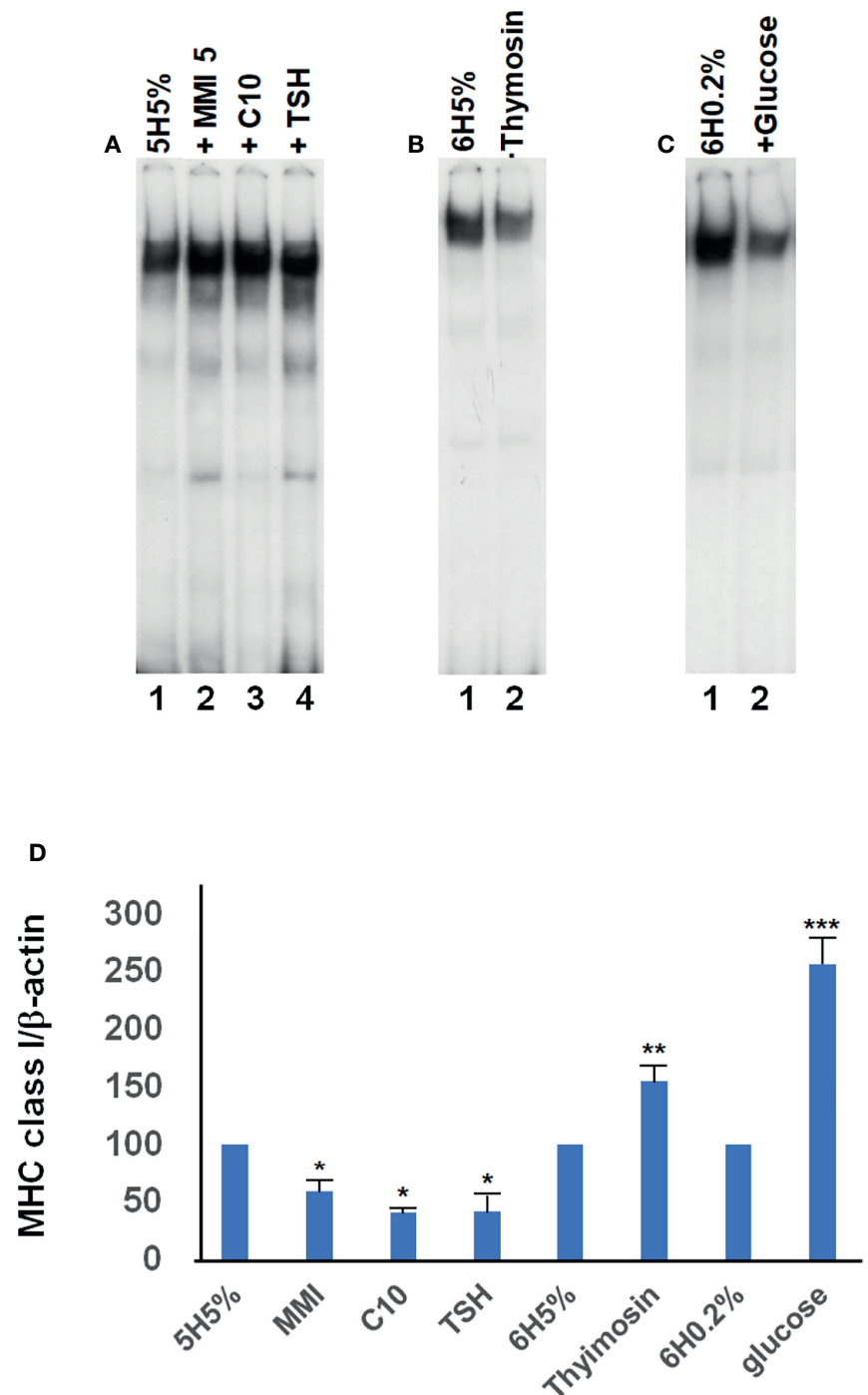

FIGURE 3 | Representative EMSAs showing the effect of different compounds on the formation of the silencer element. EMSAs were performed, as detailed in Material and Methods, using cellular extracts from FRTL-5 and the -140 bp probe that spans the region between -772 to -637 bp from the transcription start site (this fragment encloses the overlapping enhancer and silencer elements of the "tissue-specific" region). (A), Lane 1 is the incubation of the radioactive probe with extracts from control cells (5H 5\% medium, i.e. without TSH); lanes 2 to 4 show the effect of MMl 5 mM, C10 0.5 mM, and TSH 0.1 nM, respectively, on the complex formation after 36 hours of treatment. (B), lane 1 is the incubation of radioactive probe with extracts from control cells $(6 \mathrm{H} 5 \%$ medium); lanes 2 show the effect of thymosin- $\alpha 11 \mu \mathrm{g} / \mathrm{mL}$ on the complex formation after 12 hours of treatment. (C), lane 1 is the incubation of radioactive probe with extracts from control cells ( $6 \mathrm{H} 0.2 \%$ medium); lanes 2 show the effect of glucose $30 \mathrm{mM}$ on the complex formation after 48 hours of treatment. Data are from a representative experiment repeated three times with similar results. Differences are statistically significant, $p<0.05$. (D), effect of the treatments performed in EMSAs on the MHC class I RNA levels. FRTL-5 cells were grown and prepared as detailed in Materials and Methods. Data are means MHC class-l/ $\beta$-actin \pm S.D. expressed as percentages of control from three separate experiments, ${ }^{\star} \mathrm{p}<0.05$ compared to the relative control $5 \mathrm{H} 5 \%$; ${ }^{\star \star} \mathrm{p}<0.05$ compared to the relative control $6 \mathrm{H} 5 \%$; ${ }^{\star \star \star} \mathrm{p}<0.05$ compared to the relative control $6 \mathrm{H} 0.2 \%$.

and IGF-1 also increased the binding of a protein complex to a silencer element located upstream on the promoter in the "tissuespecific" region. From these results, which have highlighted a dominant role of this region in the MHC class I gene regulation, we were prompted to evaluate the effects of other factors on it.

As a first attempt we have chosen to evaluate the effect of either compounds that decrease the MHC class I gene expression, such as TSH, MMI and C10, or compounds that increase it, such as thymosin- $\alpha 1$ and glucose. TSH was chosen since it is the main regulator of thyroid growth and function. MMI is a drug widely used to treat hyperthyroidism that, beside an antithyroid effect, also has anti-inflammatory and immunosuppressive effects (42-44). C10, a phenyl derivative of MMI (17), is a more potent anti-inflammatory agent both in vitro and in vivo $(17,45)$. Thymosin- $\alpha 1$ is a drug used to stimulate the immune response (46) and one of its mechanisms of action is the increase of MHC class I expression $(20,47)$. The increased expression of MHC class I molecules on thyroid cells 


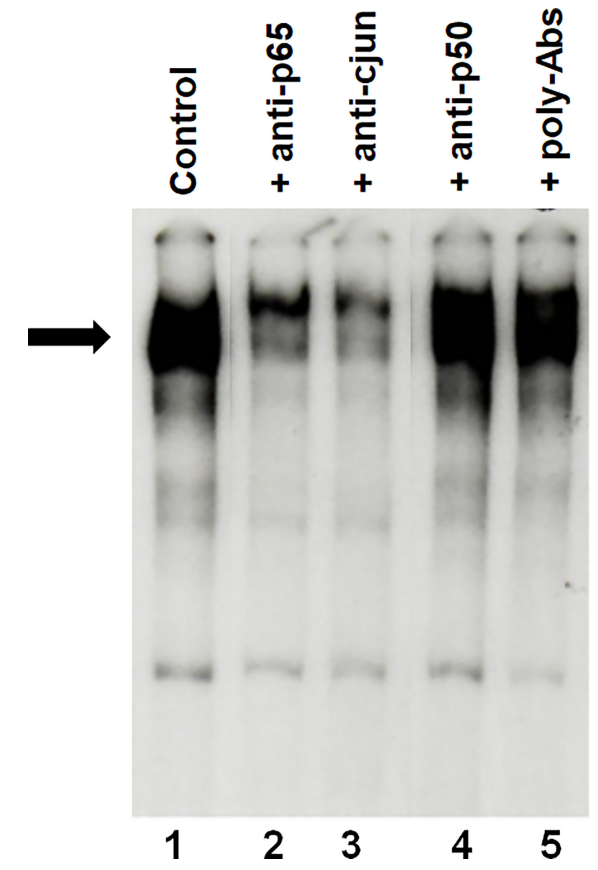

FIGURE 4 | Representative EMSAs showing the ability of antisera specific for the p65 subunit of NF-kB or c-jun to inhibit the formation of the silencer complex. EMSAs were performed, as detailed in Material and Methods, using cellular extracts from FRTL-5 and the $-140 \mathrm{bp}$ probe that spans the region between -772 to -637 bp from the transcription start site. Lane 1 is the incubation of the radioactive probe with extracts from control cells $(6 \mathrm{H} 5 \%)$; lanes 2 to 6 are the incubation of the radioactive probe with extracts from control cells after preincubation with antibodies directed against the p65 subunits of NF-kB, c-jun and the p50 subunit of NF-kB respectively; lane 5 refers to preincubation with normal polyclonal mouse lgGs as negative control. Data are from a representative experiment repeated three times with similar results. Differences are statistically significant, $p<0.05$.

induced by the high glucose levels can be involved in the higher incidence of thyroid autoimmunity associated with hyperglycemia $(48,49)$. Furthermore, an increased expression of MHC class I molecules in endothelial cells has been associated with coronary artery disease (50) and this can be related with the vascular complications induced by hyperglycemia.

In the present study we have demonstrated that in addition to insulin and IGF-1, even TSH, MMI, C10, thymosin- $\alpha 1$ and glucose regulate the silencer complex in the "tissue-specific" region and their effects on this site are in tune with the effects they have on the downstream "hormone/cytokines-sensitive" region. These data further suggest that in FRTL-5 cells the "tissue-specific" region acts as a dominant regulatory element. They also show that for most of the compounds tested the two regulatory regions of the MHC class I promoter act in concert with each other and the only exception observed so far is for insulin and IGF-1. The functional relationship between the "tissue-specific" region and the "hormone/cytokines-sensitive" region has been observed in a previous study where we evaluated the effect of insulin and IGF-1 on a reporter vector containing the full length of the MHC class I promoter with a deletion of the enhancer A element (30). The deletion of the enhancer A site resulted in the loss of the insulin/IGF-1 effect on the promoter activity. A weakness of the present work is the lack of information on the effects of other compounds involved in the autoimmune process. Further studies need to be performed in order to find whether other compounds, particularly cytokines, have a disparate response between these two regulatory regions. Moreover, further studies should evaluate the regulation of MHC class I by hormones, growth factors and cytokines in other tissues beside thyroid.

In the present study, we have also noticed that in FRTL- 5 cells the transcription factors involved in the upstream silencer complex formation are the p65 subunit of NF-kB and the AP1 family member c-jun. It must be underlined that the two primary regions that regulate MHC class I transcription in thyroid cells, that are the "tissue-specific" region and the "hormone/cytokines-sensitive" region, interact with different members of the same family of transcription factors. Indeed, the upstream silencer interact with the p65 subunit of NF-kB and $\mathrm{c}$-jun, whereas the downstream enhancer A element binds either the complex Mod-1 (formed by the heterodimer p50/fra-2) or the classic NF-kB dimer p50/p65, which has an opposite effect compared to Mod-1 $(14,15)$. Thus, it is possible that a regulatory effect in one subunit can affect the other and alter the way in which these factors regulate the promoter. Further studies are needed to deepen our knowledge on the functional interactions between these transcription factors and the promoter regions, as well as to evaluate if other transcription factors are involved.

Of particular interest is also the observation that MHC class I expression in thyroid cells is controlled by several hormones and growth factors. This hormonal regulation is considered important for the suppression of autoimmunity during hormonally induced changes in thyroid cell function, which results in an enhanced expression of potential thyroid autoantigens, such as thyroglobulin, thyroid peroxidase, and the TSH receptor $(7,8)$. Indeed, several observations suggest that the overexpression of HLA molecules on nonimmune cells has an important role in the pathogenesis of autoimmune diseases. It has been hypothesized that several insults to nonimmune cells of target tissues (such as viral infections, dsRNA, ds DNA or tissue injury) can activate the innate immune response through PRRs such as TLRs and RIG-like receptors, and induce the secretion of $\alpha$-, $\beta$ - or $\gamma$-IFN. This would result in an overexpression of MHC molecules and cytokines by the target cells, which would then recruit and activate lymphocytes and hence initiate an autoimmune response $(7,8$, $24-26,51)$. Therefore, we think it is very important to know of the mechanisms that regulate the MHC class I gene as well as the compounds that can modify them. Indeed, it is of remarkable importance to underline is the selective regulation of the distinct members of NF-kB and AP-1 by several hormones and growth factors. The hormonal regulation of the NF-kB dimers in thyroid cells is not restricted to the MHC gene. Studies performed in the FRTL-5 cells have shown that TSH can modify the composition of the NF-kB dimers activated by TNF- $\alpha$. In the absence of TSH, 


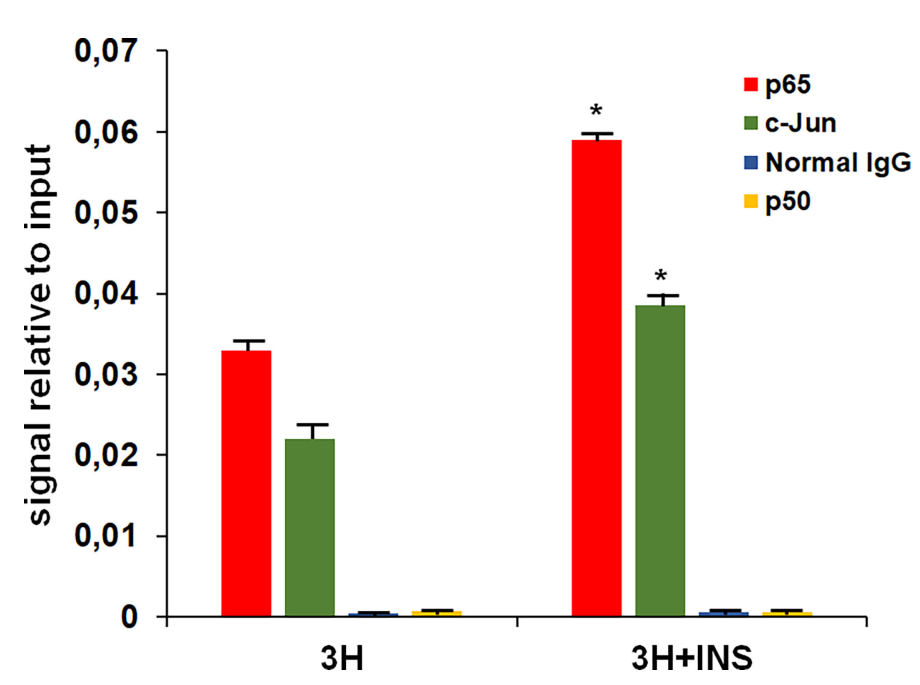

FIGURE 5 | qPCR analysis of purified DNA from ChIP performed using antibodies against the p65 subunit of NF-kB and c-jun. 3H, control cells (3H 0.2\% medium); $3 \mathrm{H}+$ INS ( $3 \mathrm{H} 0.2 \%$ medium + insulin $10 \mu \mathrm{g} / \mathrm{ml})$. Normal rabbit or mouse lgG were used as negative control in the ChIP assay. The amount of immunoprecipitated DNA in each sample is represented as signal relative to the total amount of input chromatin. Data are means \pm SD for three independent experiments. ${ }^{\star} p<0.05$ versus relevant control.

TNF- $\alpha$ treatment activates only the p50 homodimers, whereas in the presence of TSH there is also the activation of the p50/p65 heterodimers, which results in the modification of the IL- 6 gene expression (52).

The data presented herein suggest that the "tissue-specific" region represents the primary regulator of the MHC class I gene transcription in thyroid cells. They further suggest that some drugs such as MMI, its derivative $\mathrm{C} 10$ and thymosin- $\alpha 1$ regulate the binding of c-jun and the p65 subunit of NF-kB to this region. This can have an impact on the therapy of autoimmune and inflammatory diseases as well as on the treatment of cancer. Indeed, we speculate that the effectiveness of MMI in the treatment of autoimmune thyroid diseases is not only due to its antithyroid effect but also to its ability to suppress the inflammatory and immune processes. For this reason, we and other groups have studied MMI derivatives characterized by a high anti-inflammatory and immunosuppressive potency and a low or no effect on thyroid function $(17,45,53,54)$. C10 is one of these derivatives and several studies suggest its potential use in severe inflammatory diseases (45). On the other hand, the information obtained on the mechanism of action of thymosin- $\alpha 1$ are important for its use in cancer immunotherapy and to stimulate the research of new drugs with the same mechanism of action, considering that the loss of MHC class I expression is a feature of several tumors including papillary thyroid cancer (55-59).

The present study, as well as most of the studies discussed here, has been performed in the FRTL-5 cells. They are a nontransformed rat thyroid cell line in continuous culture that represents a well-defined and reproducible in-vitro model of thyroid function $(13-15,17-21,24,30,33-38)$. The reliability of the FRTL-5 cells as a model to study MHC gene regulation has been validated by studies conducted in animal models and in human tissues $(1,7,8,54,60,61)$.
In summary, our data show that the "tissue-specific" region of the MHC class I promoter is the target of several hormones and growth factors that regulate the gene expression. Future research directions should be performed to deepen the knowledge about MHC class I promoter activity in thyroid and in other tissues, either nonimmune and immune and to understand its role in autoimmune diseases and cancer.

\section{DATA AVAILABILITY STATEMENT}

The raw data supporting the conclusions of this article will be made available by the authors, without undue reservation.

\section{AUTHOR CONTRIBUTIONS}

CG and GN designed and drafted the manuscript. The experimental procedures and data analysis were performed by CG, SV, FV, IB, AG, and GN. All authors contributed to the article and approved the submitted version.

\section{ACKNOWLEDGMENTS}

This study could not have been designed and performed without the continuous help and scientific support of the late Dr. Leonard D. Kohn. The authors are also grateful to Dr. Dinah S. Singer for her intellectual contribution and for the materials she kindly provided. A grateful appreciation to Prof. Rosa Angela Giuliani for linguistic revision of the manuscript. 


\section{REFERENCES}

1. Mozes E, Kohn LD, Hakim F, Singer DS. Resistance of MHC Class I-Deficient Mice to Experimental Systemic Lupus Erythematosus. Science (1993) 261:913. doi: $10.1126 /$ science 8316860

2. Serreze DV, Chapman HD, Varnum DS, Gerling I, Leiter EH, Shultz LD. Initiation of Autoimmune Diabetes in NOD/Lt Mice Is MHC Class IDependent. J Immunol (1997) 158:3978-86.

3. Richardson SJ, Rodriguez-Calvo T, Gerling IC, Mathews CE, Kaddis JS, Russell MA, et al. Islet Cell Hyperexpression of HLA Class I Antigens: A Defining Feature in Type 1 Diabetes. Diabetologia (2016) 59:2448-58. doi: 10.1007/s00125-016-4067-4

4. Ito T, Meyer KC, Ito N, Paus R. Immune Privilege and the Skin. Curr Dir Autoimmun (2008) 10:27-52. doi: 10.1159/000131412

5. Gono T, Katsumata Y, Kawaguchi Y, Soejima M, Wakasugi D, Miyawaki M, et al. Selective Expression of MHC Class I in the Affected Muscle of a Patient With Idiopathic Inflammatory Myopathy. Clin Rheumatol (2009) 28:873-6. doi: 10.1007/s10067-009-1172-5

6. René C, Lozano C, Eliaou J-F. Expression of Classical HLA Class I Molecules: Regulation and Clinical Impacts. HLA (2016) 87:338-49. doi: 10.1111/ $\tan .12787$

7. Kohn LD, Napolitano G, Singer DS, Molteni M, Scorza R, Shimojo N, et al. Graves' Disease: A Host Defense Mechanism Gone Awry. Int Rev Immunol (2000) 19:633-64. doi: 10.3109/08830180009088516

8. Luo Y, Yoshihara A, Oda K, Ishido Y, Suzuki K. Excessive Cytosolic DNA Fragments as a Potential Trigger of Graves' Disease: An Encrypted Message Sent by Animal Models. Front Endocrinol (2016) 7:144. doi: 10.3389/ fendo.2016.00144

9. Gianfran C, Pisapia L, Picascia S, Strazzullo M, Del Pozzo G. Expression Level of Risk Genes of MHC Class II Is a Susceptibility Factor for Autoimmunity: New Insights. J Autoimmun (2018) 89:1-10. doi: 10.1016/j.jaut.2017.12.016

10. Verma S, Hutchings P, Guo J, McLachlan S, Rapoport B, Cooke A. Role of MHC Class I Expression and CD8(+) T Cells in the Evolution of IodineInduced Thyroiditis in NOD-H2(h4) and NOD Mice. Eur J Immunol (2000) 30:1191-202. doi: 10.1002/(SICI)1521-4141(200004)30:4<1191::AIDIMMU1191>3.0.CO;2-L

11. Weider T, Richardson SJ, Morgan NG, Paulsen TH, Dahl-Jørgensen K, Hammerstad SS. Upregulation of HLA Class I and Antiviral Tissue Responses in Hashimoto's Thyroiditis. Thyroid (2020) 30:432-42. doi: $10.1089 /$ thy.2019.0607

12. Gilhar A, Laufer-Britva R, Keren A, Paus R. Frontiers in Alopecia Areata Pathobiology Research. J Allergy Clin Immunol (2019) 144:1478-89. doi: 10.1016/j.jaci.2019.08.035

13. Saji M, Shong M, Napolitano G, Palmer LA, Taniguchi SI, Ohmori M, et al. Regulation of Major Histocompatibility Complex Class-I Gene Expression in Thyroid Cells: Role of the cAMP Response Element-Like Sequence. J Biol Chem (1997) 272:20096-107. doi: 10.1074/jbc.272.32.20096

14. Giuliani C, Saji M, Napolitano G, Palmer LA, Taniguchi SI, Shong M, et al. Hormonal Modulation of Major Histocompatibility Complex Class I Gene Expression Involves an Enhancer A-Binding Complex Consisting of Fra-2 and the P50 Subunit of NF-Kappa B. J Biol Chem (1995) 270:11453-62. doi: $10.1074 / j b c .270 .19 .11453$

15. Taniguchi S-I, Shong M, Giuliani C, Napolitano G, Saji M, Montani V, et al. Iodide Suppression of Major Histocompatibility Class I Gene Expression in Thyroid Cells Involves Enhancer A and the Transcription Factor NF-Kb. Mol Endocrinol (1998) 12:19-33. doi: 10.1210/mend.12.1.0052

16. Giuliani C, Bucci I, Napolitano G. The Role of the Transcription Factor Nuclear Factor-Kappa B in Thyroid Autoimmunity and Cancer. Front Endocrinol (2018) 9:471. doi: 10.3389/fendo.2018.00471

17. Giuliani C, Bucci I, Montani V, Singer DS, Monaco F, Kohn LD, et al. Regulation of Major Histocompatibility Complex Gene Expression in Thyroid Epithelial Cells by Methimazole and Phenylmethimazole. J Endocrinol (2010) 204:57-66. doi: 10.1677/JOE-09-0172

18. Napolitano G, Bucci I, Giuliani C, Massafra C, Di Petta C, Devangelio E, et al. High Glucose Levels Increase Major Histocompatibility Complex Class I Gene Expression in Thyroid Cells and Amplify Interferon- $\gamma$ Action. Endocrinology (2002) 143:1008-17. doi: 10.1210/endo.143.3.8674
19. Napolitano G, Montani V, Giuliani C, Di Vincenzo S, Bucci I, Todisco V, et al. Transforming Growth Factor- $\beta 1$ Down-Regulation of Major Histocompatibility Complex Class I in Thyrocytes: Coordinate Regulation of Two Separate Elements by Thyroid-Specific as Well as Ubiquitous Transcription Factors. Mol Endocrinol (2000) 14:486-505. doi: 10.1210/ mend.14.4.0454

20. Giuliani C, Napolitano G, Mastino AS, Di Vincenzo S, D’Agostini C, Grelli S, et al. Thymosin- $\alpha 1$ Regulates MHC Class-I Expression in FRTL-5 Cells at a Transcriptional Level. Eur J Immunol (2000) 30:778-86. doi: 10.1002/15214141(200003)30:3<778::AID-IMMU778>3.0.CO,2-I

21. Grassadonia A, Tinari N, Fiorentino B, Suzuki K, Nakazato M, De Tursi M, et al. The $90 \mathrm{~K}$ Protein Increases Major Histocompatibility Complex Class I Expression and Is Regulated by Hormones, Gamma-Interferon, and DoubleStrand Polynucleotides. Endocrinology (2004) 145:4728-36. doi: 10.1210/ en.2004-0506

22. Daar AS, Fuggle SV, Fabre JW, Ting A, Morris PJ. The Detailed Distribution of HLA-A, B, C Antigens in Normal Human Organs. Transplantation (1984) 38:287-92. doi: 10.1097/00007890-198409000-00018

23. Kotekar AS, Weissman JD, Gegonne A, Cohen H, Singer DS. Histone Modifications, But Not Nucleosomal Positioning, Correlate With Major Histocompatibility Complex Class I Promoter Activity in Different Tissues In Vivo. Mol Cell Biol (2008) 28:7323-36. doi: 10.1128/MCB.00889-08

24. Harii N, Lewis CJ, Vasko V, McCall K, Benavides-Peralta U, Sun X, et al. Thyrocytes Express a Functional Toll-Like Receptor 3: Overexpression can be Induced by Viral Infection and Reversed by Phenylmethimazole and Is Associated With Hashimoto's Autoimmune Thyroiditis. Mol Endocrinol (2005) 19:1231-50. doi: 10.1210/me.2004-0100

25. Kawashima A, Yamazaki K, Hara T, Akama T, Yoshihara A, Sue M, et al. Demonstration of Innate Immune Responses in the Thyroid Gland: Potential to Sense Danger and a Possible Trigger for Autoimmune Reactions. Thyroid (2013) 23:477-87. doi: 10.1089/thy.2011.0480

26. Kawashima A, Tanigawa K, Akama T, Wu H, Sue M, Yoshihara A, et al. Fragments of Genomic DNA Released by Injured Cells Activate Innate Immunity and Suppress Endocrine Function in the Thyroid. Endocrinology (2011) 152:1702-12. doi: 10.1210/en.2010-1132

27. Newby BN, Mathews CE. Type I Interferon Is a Catastrophic Feature of the Diabetic Islet Microenvironment. Front Endocrinol (2017) 8:232. doi: 10.3389/ fendo.2017.00232

28. Luo YB, Mastaglia FL. Dermatomyositis, Polymyositis and Immune-Mediated Necrotising Myopathies. Biochim Biophys Acta (2015) 1852:622-32. doi: 10.1016/j.bbadis.2014.05.034

29. Bhattarai S, Ghannam K, Krause S, Benveniste O, Marg A, de Bruin G, et al. The Immunoproteasomes Are Key to Regulate Myokines and MHC Class I Expression in Idiopathic Inflammatory Myopathies. J Autoimmun (2016) 75:118-29. doi: 10.1016/j.jaut.2016.08.004

30. Giuliani C, Saji M, Bucci I, Fiore G, Liberatore M, Singer DS, et al. Transcriptional Regulation of Major Histocompatibility Complex Class I Gene by Insulin and IGF-I in FRTL-5 Thyroid Cells. J Endocrinol (2006) 189:605-15. doi: 10.1677/joe.1.06486

31. Weissman JD, Singer DS. A Complex Regulatory DNA Element Associated With a Major Histocompatibility Complex Class I Gene Consists of Both a Silencer and an Enhancer. Mol Cell Biol (1991) 11:4217-27. doi: 10.1128/mcb.11.8.4217

32. Murphy C, Nikodem D, Howcroft K, Weissman JD, Singer DS. Active Repression of Major Histocompatibility Complex Class I Genes in Human Neuroblastoma Cell Line. J Biol Chem (1996) 271:30992-9. doi: 10.1074/jbc.271.48.30992

33. Törnquist K, Sukumaran P, Kemppainen K, Löf C, Viitanen T. Canonical Transient Receptor Potential Channel 2 (TRPC2): Old Name-New Games. Importance in Regulating of Rat Thyroid Cell Physiology. Pflugers Arch (2014) 466:2025-34. doi: 10.1007/s00424-014-1509-z

34. Wen G, Ringseis R, Eder K. Endoplasmic Reticulum Stress Inhibits Expression of Genes Involved in Thyroid Hormone Synthesis and Their Key Transcriptional Regulators in FRTL-5 Thyrocytes. PloS One (2017) 12(11): e0187561. doi: 10.1371/journal.pone.0187561

35. Ambesi Impiombato FSinventor; Interthyr Research Foundation Inc, assignee. United States Patent US 4608341: USA patent (1986).

36. Lin R, Hogen V, Cannon S, Marion KM, Fenton MS, Hershman JM. Stability of Recombinant Human Thyrotropin Potency Based on Bioassay in FRTL-5 Cells. Thyroid (2010) 20:1139-43. doi: 10.1089/thy.2009.0408 
37. Giuliani C, Bucci I, Di Santo S, Rossi C, Grassadonia A, Mariotti M, et al. Resveratrol Inhibits Sodium/Iodide Symporter Gene Expression and Function in Rat Thyroid Cells. PloS One (2014) 9(9):e107936. doi: 10.1371/ journal.pone.0107936

38. Giuliani C, Iezzi M, Ciolli L, Hysi A, Bucci I, Di Santo S, et al. Resveratrol has Anti-Thyroid Effects Both In Vitro and In Vivo. Food Chem Toxicol (2017) 107:237-47. doi: 10.1016/j.fct.2017.06.044

39. Dignam J, Lebovitz R, Roeder R. Accurate Transcription Initiation by RNA Polymerase II in a Soluble Extract From Isolated Mammalian Nuclei. Nucleic Acids Res (1983) 11:1475-89. doi: 10.1093/nar/11.5.1475

40. Saji M, Moriarty J, Ban T, Kohn LD, Singer DS. Hormonal Regulation of Major Histocompatibility Complex Class I Genes in Rat Thyroid FRTL-5 Cells: Thyroid-Stimulating Hormone Induces a cAMP-Mediated Decrease in Class I Expression. Proc Natl Acad Sci USA. (1992) 89:1944-19488. doi: 10.1073/pnas.89.5.1944

41. Saji M, Moriarty J, Ban T, Singer DS, Kohn LD. Major Histocompatibility Complex Class I Gene Expression in Rat Thyroid Cells Is Regulated by Hormones, Methimazole, and Iodide as Well as Interferon. J Clin Endocrinol Metab (1992) 75:871-8. doi: 10.1210/jcem.75.3.1381373

42. Mozes E, Zinger H, Kohn LD, Singer DS. Spontaneous Autoimmune Disease in (NZB X NZW) F1 Mice is Ameliorated by Treatment With Methimazole. J Clin Immunol (1998) 18:106-13. doi: 10.1023/a:1023242732212

43. Wang P, Sun SH, Silver PB, Chan CC, Agarwal RK, Wiggert B, et al. Methimazole Protects From Experimental Autoimmune Uveitis (EAU) by Inhibiting Antigen Presenting Cell Function and Reducing Antigen Priming. J Leukoc Biol (2003) 73:57-64. doi: 10.1189/jlb.0102047

44. Starosz A, Stożek K, Moniuszko M, Grubczak K, Bossowski A. Evaluating the Role of Circulating Dendritic Cells in Methimazole-Treated Pediatric Graves' Disease Patients. Genes (2021) 12:164. doi: 10.3390/genes12020164

45. Giuliani C, Bucci I, Napolitano G. Phenylmethimazole Is a Candidate Drug for the Treatment of Severe Forms of Coronavirus Disease 2019 (COVID-19) as Well as Other Virus-Induced "Cytokines Storm". Med Hypotheses (2021) 146:110473. doi: 10.1016/j.mehy.2020.110473

46. Dominari A, Hathaway Iii D, Pandav K, Matos W, Biswas S, Reddy G, et al. Thymosin Alpha 1: A Comprehensive Review of the Literature. World J Virol (2020) 9:67-78. doi: 10.5501/wjv.v9.i5.67

47. Garaci E, Favalli C, Pica F, Sinibaldi Vallebona P, Palamara AT, Matteucci C, et al. Thymosin Alpha 1: From Bench to Bedside. Ann N Y Acad Sci (2007) 1112:225-34. doi: 10.1196/annals.1415.044

48. Vitacolonna E, Lapolla A, Di Nenno B, Passante A, Bucci I, Giuliani C, et al. Gestational Diabetes and Thyroid Autoimmunity. Int J Endocrinol (2012) 2012:867415. doi: 10.1155/2012/867415

49. Sarfo-Kantanka O, Sarfo FS, Ansah EO, Yorke E, Akpalu J, Nkum BC, et al. Frequency and Determinants of Thyroid Autoimmunity in Ghanaian Type 2 Diabetes Patients: A Case-Control Study. BMC Endocr Disord (2017) 17(1):2. doi: 10.1186/s12902-016-0152-4

50. Foglieni C, Maisano F, Dreas L, Giazzon A, Ruotolo G, Ferrero E, et al. Mild Inflammatory Activation of Mammary Arteries in Patients With Acute Coronary Syndromes. Am J Physiol Heart Circ Physiol (2008) 294:H2831-7. doi: 10.1152/ajpheart.91428.2007

51. Pisetsky DS. The Role of Innate Immunity in the Induction of Autoimmunity. Autoimmun Rev (2008) 8:69-72. doi: 10.1016/j.autrev.2008.07.028

52. Kikumori T, Kambe F, Nagaya T, Funahashi H, Seo H. Thyrotropin Modifies Activation of Nuclear Factor kB by Tumour Necrosis Factor $\alpha$ in Rat Thyroid Cell Line. Biochem J (2001) 354:573-9. doi: 10.1042/bj3540573
53. Alapati A, Deosarkar SP, Lanier OL, Qi C, Carlson GE, Burdick MM, et al. Simple Modifications to Methimazole That Enhance Its Inhibitory Effect on Tumor Necrosis Factor- $\alpha$-Induced Vascular Cell Adhesion Molecule-1 Expression by Human Endothelial Cells. Eur J Pharmacol (2015) 751:59-66. doi: 10.1016/j.ejphar.2015.01.032

54. Noori MS, O'Brien JD, Champa ZJ, Deosarkar SP, Lanier OL, Qi C, et al. Phenylmethimazole and a Thiazole Derivative of Phenylmethimazole Inhibit IL-6 Expression by Triple Negative Breast Cancer Cells. Eur J Pharmacol (2017) 803:130-7. doi: 10.1016/j.ejphar.2017.03.049

55. Angell TE, Lechner MG, Jang JK, LoPresti JS, Epstein AL. MHC Class I Loss Is a Frequent Mechanism of Immune Escape in Papillary Thyroid Cancer That Is Reversed by Interferon and Selumetinib Treatment In Vitro. Clin Cancer Res (2014) 20:6034-44. doi: 10.1158/1078-0432.CCR-14-0879

56. Han LT, Hu JQ, Ma B, Wen D, Zhang T-T, Lu Z-W, et al. IL-17A Increases MHC Class I Expression and Promotes T Cell Activation in Papillary Thyroid Cancer Patients With Coexistent Hashimoto's Thyroiditis. Diagn Pathol (2019) 14:52. doi: 10.1186/s13000-019-0832-2

57. Lu ZW, Hu JQ, Liu WL, Wen D, Wei WJ, Wang YL, et al. IL-10 Restores MHC Class I Expression and Interferes With Immunity in Papillary Thyroid Cancer With Hashimoto Thyroiditis. Endocrinology (2020) 161(10):bqaa062. doi: 10.1210/endocr/bqaa062

58. Zitvogel L, Perreault C, Finn OJ, Kroemer G. Beneficial Autoimmunity Improves Cancer Prognosis. Nat Rev Clin Oncol (2021) 18:591-602. doi: 10.1038/s41571-021-00508-x

59. Jongsma MLM, Neefjes J, Spaapen RM. Playing Hide and Seek: Tumor Cells in Control of MHC Class I Antigen Presentation. Mol Immunol (2021) 136:36-44. doi: 10.1016/j.molimm.2021.05.009

60. Schuppert F, Taniguchi S, Schröder S, Dralle H, von zur Mühlen A, Kohn LD. In Vivo and In Vitro Evidence for Iodide Regulation of Major Histocompatibility Complex Class I and Class II Expression in Graves' Disease. J Clin Endocrinol Metab (1996) 81:3622-8. doi: 10.1210/jcem.81.10.8855812

61. Schuppert F, Ehrenthal D, Frilling A, Suzuki K, Napolitano G, Kohn LD. Increased Major Histocompatibility Complex (MHC) Expression in Nontoxic Goiters Is Associated With Iodide Depletion, Enhanced Ability of the Follicular Thyroglobulin to Increase MHC Gene Expression, and Thyroid Autoantibodies. J Clin Endocrinol Metab (2000) 85:858-67. doi: 10.1210/ jcem.85.2.6394

Conflict of Interest: The authors declare that the research was conducted in the absence of any commercial or financial relationships that could be construed as a potential conflict of interest.

Publisher's Note: All claims expressed in this article are solely those of the authors and do not necessarily represent those of their affiliated organizations, or those of the publisher, the editors and the reviewers. Any product that may be evaluated in this article, or claim that may be made by its manufacturer, is not guaranteed or endorsed by the publisher.

Copyright (C) 2021 Giuliani, Verrocchio, Verginelli, Bucci, Grassadonia and Napolitano. This is an open-access article distributed under the terms of the Creative Commons Attribution License (CC BY). The use, distribution or reproduction in other forums is permitted, provided the original author(s) and the copyright owner(s) are credited and that the original publication in this journal is cited, in accordance with accepted academic practice. No use, distribution or reproduction is permitted which does not comply with these terms. 